Article

\title{
Effect of the Structure of Alkyl Salicylaldoxime on Extraction of Copper(II)
}

\author{
Liqing Li ${ }^{1,3}$, Yi Wang ${ }^{1}$, Wenjuan An ${ }^{1}$ and Shenxu Bao ${ }^{2,3, *}$ \\ 1 School of Metallurgical and Chemical Engineering, Jiangxi University of Science and Technology, \\ Ganzhou 34100, China; liliqing79@126.com (L.L.); wangyi19920719@126.com (Y.W.); \\ anwenjuan19920604@126.com (W.A.) \\ 2 School of Resources and Environmental Engineering, Wuhan University of Technology, \\ Wuhan 430070, China \\ 3 School of Chemical Engineering, The University of Queensland, Brisbane 4072, Australia \\ * Correspondence: sxbao@whut.edu.cn; Tel.: +86-27-87212127
}

Academic Editor: M. Thaddeus Ityokumbul

Received: 18 January 2017; Accepted: 29 March 2017; Published: 20 April 2017

\begin{abstract}
Four kinds of alkyl salicylaldoxime (AS) were investigated to probe the effect of molecular structure on the extraction of $\mathrm{Cu}(\mathrm{II})$. With the augment of $\mathrm{R}$ groups, tert-octylsalicylaldoxime and nonylsalicylaldoxime have much stronger extraction ability for $\mathrm{Cu}(\mathrm{II})$ than salicylaldoxime and tert-butylsalicylaldoxime, which is consistent with the rise of hydrophobicity (Log P) of the extractants. The umbrella structure of the R group can endow tert-octylsalicylaldoxime with stronger steric-hindrance effect than nonylsalicylaldoxime, which results in the better separation efficiency of $\mathrm{Cu}$ (II) from $\mathrm{Fe}$ (III) for tert-octylsalicylaldoxime. The extraction ability of the extractants for $\mathrm{Cu}$ (II) is related to the hydrophobicity and molecular size, as predicted from quantum chemistry calculation.
\end{abstract}

Keywords: alkyl salicylaldoxime; Copper(II) ion; molecular structure; extraction efficiency; separation

\section{Introduction}

With increased demand for copper, rich copper deposits are rapidly decreasing, and people are now focusing attention on copper recovery from low-grade copper ore or/and secondary copper resources [1,2]. The hydrometallurgical technique involving crushing, leaching, solvent extraction (SX), and electrowinning is being applied to recover copper from these low-grade copper resources $[3,4]$. $\mathrm{SX}$ is one key unit operation in the hydrometallurgical process because it determines the copper separation from the leaching solutions and also has great influence on the following electrowinning efficiency [5]. Thus, it is vital to find or synthesize effective extraction reagents for copper recovery and production.

Alkyl salicylaldoximes (AS) - the $\mathrm{N}-\mathrm{O}$ type chelating organic agents-are widely-used extractants which present excellent extraction efficiency for $\mathrm{Cu}(\mathrm{II})$ [6,7]. AS are comprised of a benzene ring, phenolic hydroxyl, ortho-directing oximido, and para-directing alkyl (i.e., $R$ group). In this group of chemical compounds, the para-directing $\mathrm{R}$ group has great impact on their charge distribution, steric-hindrance effect, and so on, which determines their extraction ability for $\mathrm{Cu}(\mathrm{II})[8,9]$. At present, AS are produced by bio-extraction and artificial synthesis, with the artificial synthesis route being the dominant technique for the production of AS [10,11]. It was reported that many types of AS with different R groups (e.g., nonyl, decyl, and dodecyl) have been synthesized in the laboratory [12-16]. Some researchers investigated the extraction ability of AS with more than 12 carbon atoms in the R group for $\mathrm{Cu}(\mathrm{II})$. It was shown that these AS presented bad fluidity and phase separation during SX, which resulted in the unsatisfactory extraction ability for $\mathrm{Cu}$ (II) [11]. Therefore, one of the most widely used AS is 5-nonylsalicylaldoxime (or nonylsalicylaldoxime) where the R group is a straight chain containing nine carbon atoms. It has good fluidity and steric-hindrance effect, and has been widely 
used to extract $\mathrm{Cu}(\mathrm{II})$ as the main effective component in the common commercial extractants LIX984, LIX984N, P50, and so on. However, there is little information in the literature about the performance of AS with the carbon atoms less than nine and/or non-straight chains in the R groups on the extraction of $\mathrm{Cu}(\mathrm{II})$.

In this study, two kinds of AS with non-straight R groups-one being tert-butylsalicylaldoxime with four carbon atoms in the R group and the other tert-octylsalicylaldoxime with eight carbon atoms in the $\mathrm{R}$ group-were synthesized in laboratory. We compared their extraction ability for $\mathrm{Cu}$ (II) with two other commercial salicylaldoxime-based extractants: salicylaldoxime without the R group and nonylsalicylaldoxime. Besides, the effect of the R group on the structure of the four kinds of reagents and the $\mathrm{Cu}$ (II) extraction were also discussed. This study not only provides useful guidance for the design and development of salicylaldoxime-based extractants for $\mathrm{Cu}(\mathrm{II})$ extraction, but also has significance for the exploitation and utilization of complex copper resources.

\section{Experimental}

\subsection{Materials}

tert-Butylsalicylaldoxime and tert-octylsalicylaldoxime were synthesized by using para-tert-butyl phenol (purity $>95 \%$ ) and para-tert-octyl phenol (purity $>97 \%$ ) as raw materials, respectively, and the mixture of methanol (purity $>99 \%$ ) and methylbenzene (purity $>99 \%$ ) as solvent through sequential salt forming reaction, acylation reaction, oximation reaction, and acidification reaction. The detailed synthesis procedures can be seen in [17]. The purity of the synthesized chemical reagents is no less than $95 \%$ according to the liquid chromatographic analysis (LC-8A, Shimadzu, Kyoto, Japan). Salicylaldoxime (analytical grade) and nonylsalicylaldoxime (analytical grade) were obtained from Sinopharm Chemical Reagent Co., Ltd. (Beijing, China); Kerosene (analytical grade) was purchased from Shanghai Rare-Earth Chemical Co., Ltd. (Shanghai, China), was washed with concentrated $\mathrm{H}_{2} \mathrm{SO}_{4}$ twice to eliminate the influence of unsaturated hydrocarbon, and was then washed to neutrality with deionized water before use. The $\mathrm{Cu}$ (II) sulfate, $\mathrm{Fe}$ (III) sulfate, and sulfuric acid obtained from Tianjin Kaitong Chemical Co., Ltd. (Tianjin, China) were also of analytical grade.

\subsection{Methods}

\subsubsection{Extraction of $\mathrm{Cu}(\mathrm{II})$ and $\mathrm{Fe}(\mathrm{III})$}

The organic phases with different concentrations of extractants were prepared by dissolving the corresponding reagents in the pretreated kerosene. The $\mathrm{Cu}$ (II) solution and $\mathrm{Fe}(\mathrm{III})$ solution were prepared by dissolving $\mathrm{Cu}$ (II) sulfate and $\mathrm{Fe}$ (II) sulfate in diluted sulfuric acid, respectively. The extraction of $\mathrm{Cu}$ (II) by the four kinds of extractants was carried out at room temperature and atmospheric pressure. The separation factors of the extractants for $\mathrm{Cu}(\mathrm{II})$ and $\mathrm{Fe}(\mathrm{III})\left(\beta_{\mathrm{Cu} / \mathrm{Fe}}\right)$ were evaluated by

$$
\beta_{\mathrm{Cu} / \mathrm{Fe}}=\frac{\mathrm{C}_{\mathrm{Cu}(\mathrm{O})} \cdot \mathrm{C}_{\mathrm{Fe}(\mathrm{A})}}{\mathrm{C}_{\mathrm{Cu}(\mathrm{A})} \cdot \mathrm{C}_{\mathrm{Fe}(\mathrm{O})}}
$$

where $\mathrm{C}_{\mathrm{Cu}(\mathrm{O})}$ and $\mathrm{C}_{\mathrm{Cu}(\mathrm{A})}$ indicate the concentration of $\mathrm{Cu}(\mathrm{II})$ in organic phase and aqueous phase $(\mathrm{g} / \mathrm{L})$, respectively, and $\mathrm{C}_{\mathrm{Fe}(\mathrm{O})}$ and $\mathrm{C}_{\mathrm{Fe}(\mathrm{A})}$ indicate the concentration of $\mathrm{Fe}(\mathrm{III})$ in organic phase and aqueous phase $(\mathrm{g} / \mathrm{L})$, respectively. The concentration of metal ions-including $\mathrm{Cu}$ (II) and $\mathrm{Fe}(\mathrm{III})$ - in the organic phase $\left(\mathrm{C}_{\text {metal(}(\mathrm{O})}\right)$ can be obtained by

$$
\mathrm{C}_{\text {metal }(\mathrm{O})}=\frac{\left(\mathrm{C}_{\text {metal }(\mathrm{A})}^{0}-\mathrm{C}_{\operatorname{meta}(\mathrm{A})}^{1}\right) \cdot V_{(\mathrm{A})}}{V_{(\mathrm{O})}}
$$

where $C_{\text {metal(A) }}^{0}$ and $C_{\text {metal }(A)}^{1}$ are the metal concentrations in aqueous solutions before and after extraction $(\mathrm{g} / \mathrm{L})$, respectively. $V_{(\mathrm{A})}$ is the volume of aqueous phase (L) and $V_{(\mathrm{O})}$ is the volume 
of organic phase (L). The concentration of $\mathrm{Cu}$ (II) and $\mathrm{Fe}(\mathrm{III})$ in aqueous solution was analyzed by inductively coupled plasma-atomic emission spectrometry (ICP-AES).

\subsubsection{The Structure Properties of Reagents}

The molecular structures of the four organic reagents were first drawn by Chemoffice 2010, then the molecular sizes of the extractants were calculated by Connolly Solvent-Excluded Volume method in Chemoffice 2010 [18], and their hydrophobicity (Log P) was also calculated by Chemoffice 2010. The optimum 3-D structures of the extractants were obtained based on the optimization using HF/3-21 G (d) basis set in Gaussian.

\section{Results and Discussion}

\subsection{The Structures of the Extractants}

The calculated molecular structures of the four salicylaldoxime-based extractants are shown in Figure 1, which can be verified by nuclear magnetic resonance and mass spectrograph. It can be clearly seen that the four extractants have similar molecular structures, except for the R groups linked to the benzene rings (Figure 1). Thus, their different extraction ability for metals may be due to the molecular structures which are influenced by the R groups.

\subsection{The Extraction of $\mathrm{Cu}(\mathrm{II})$}

Under the conditions of the initial $\mathrm{Cu}(\mathrm{II})$ concentration of $1.92 \mathrm{~g} \cdot \mathrm{L}^{-1}, 15 \%(v / v)$ of extractants and the phase ratio (aqueous phase to organic phase) of 1, the single-stage extraction efficiency for $\mathrm{Cu}$ (II) after $3 \mathrm{~min}$ at different initial $\mathrm{pH}$ is shown in Figure 2.

It is observed that nonylsalicylaldoxime and tert-octylsalicylaldoxime present a similar trend for $\mathrm{Cu}$ (II) extraction with $\mathrm{pH}$ (see Figure 2). The $\mathrm{Cu}$ (II) extraction efficiency initially increased with $\mathrm{pH}$ and then decreased after $\mathrm{pH} 3-4$. Although salicylaldoxime and tert-butylsalicylaldoxime showed by far the weaker extraction capacity for $\mathrm{Cu}$ (II) than nonylsalicylaldoxime and tert-octylsalicylaldoxime, their extraction efficiencies for $\mathrm{Cu}(\mathrm{II})$ were also slightly higher at $\mathrm{pH}$ of 3-4 than at other $\mathrm{pH}$ values (Figure 2). Salicylaldoxime-based extractants are acid organics, and they chelate $\mathrm{Cu}(\mathrm{II})$ in a 2:1 ratio, as shown in Figure 3 [19].

With the rise of $\mathrm{pH}$, the above extraction reaction shifts towards the right and the metal extraction efficiency also increases, which is why the $\mathrm{Cu}(\mathrm{II})$ extraction efficiency initially increased with $\mathrm{pH}$ and reached a plateau at $\mathrm{pH} 3-4$. The extraction efficiency declined after the $\mathrm{pH}$ exceeds 4 , because $\mathrm{Cu}$ (II) presents solid or colloidal particle forms in high $\mathrm{pH}$ solutions, which may interfere with its extraction [19].

At $\mathrm{pH}=4$, salicylaldoxime, tert-butylsalicylaldoxime, tert-octylsalicylaldoxime, and nonylsalicylaldoxime could extract $5.15 \%, 9.25 \%, 91.53 \%$, and $92.11 \%$ of $\mathrm{Cu}$ (II) from the solutions, respectively (Figure 2), indicating that their extraction ability for $\mathrm{Cu}(\mathrm{II})$ is enhanced with the increase of carbon chain length in the $\mathrm{R}$ groups linked to the benzene rings. As the carbon atom number in the R group increases to eight, tert-octylsalicylaldoxime presents a similar extraction capacity to nonylsalicylaldoxime, with nine carbon atoms in the R group. 


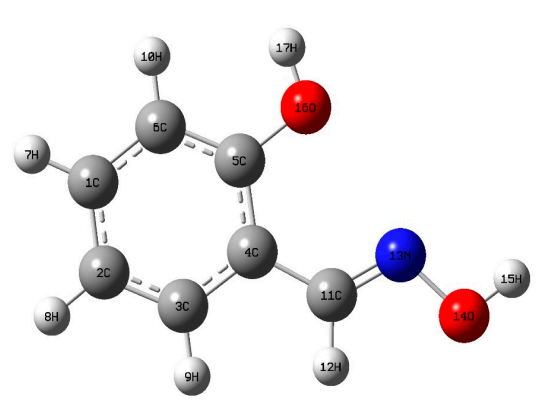

(A)

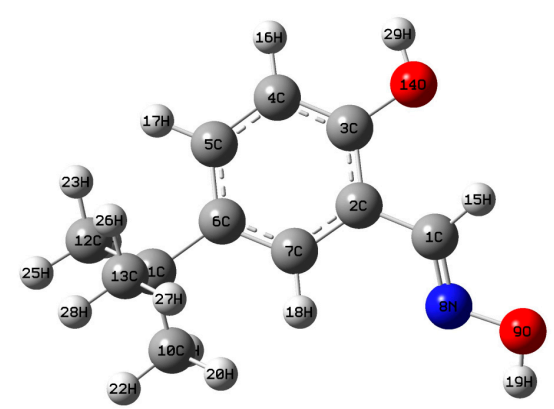

(B)

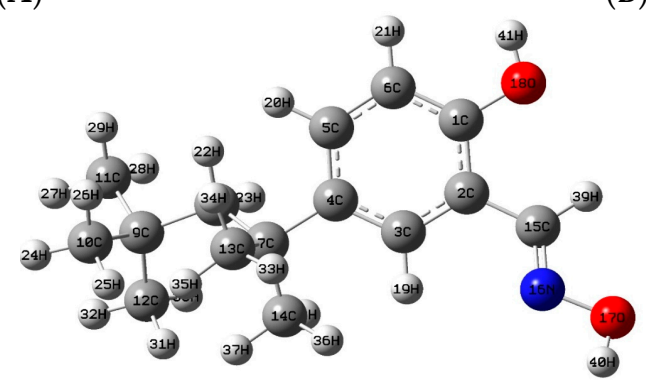

(C)

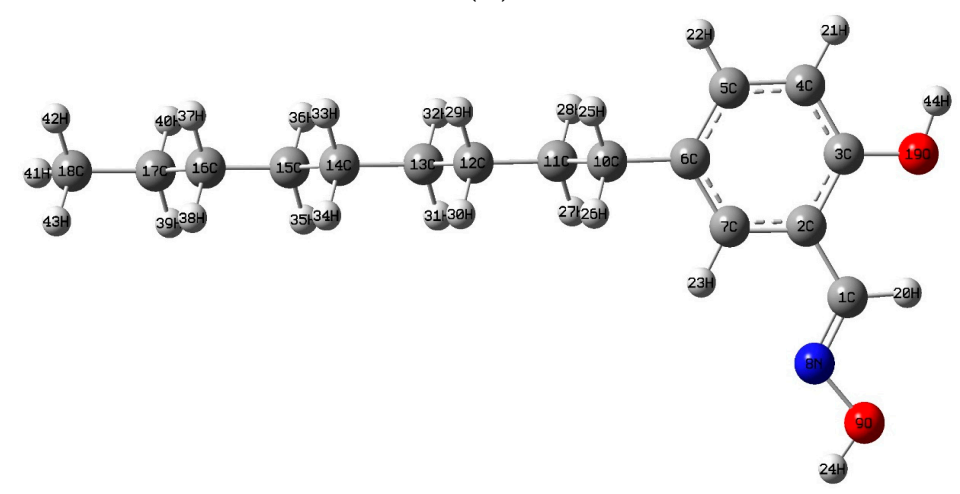

(D)

Figure 1. The optimum structures of four kinds of extractants: (A) salicylaldoxime; (B) tert-butylsalicylaldoxime; (C) tert-octylsalicylaldoxime; (D) nonylsalicylaldoxime.

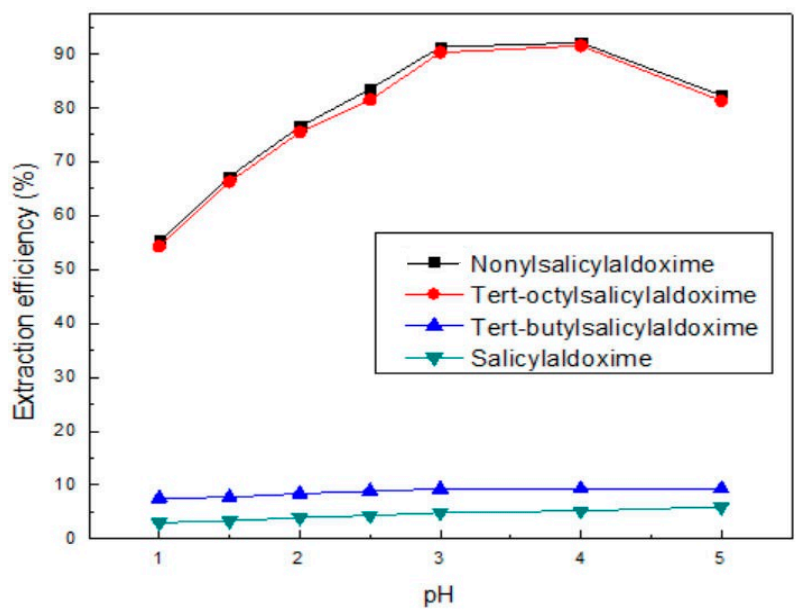

Figure 2. Effect of initial $\mathrm{pH}$ of aqueous phases on the extraction efficiency of $\mathrm{Cu}(\mathrm{II})$. 


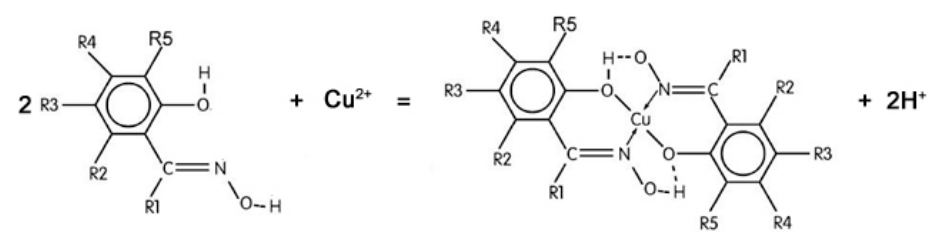

Figure 3. The reaction between salicylaldoxime-based extractants and $\mathrm{Cu}(\mathrm{II})$.

\subsection{Separation of $\mathrm{Cu}(\mathrm{II})$ and $\mathrm{Fe}(\mathrm{III})$}

The main raw ores for copper extraction are refractory complex copper sulfides and copper oxide ores, including chalcopyrite $\left(\mathrm{CuFeS}_{2}\right)$, chalmersite $\left(\mathrm{CuFe}_{2} \mathrm{~S}_{3}\right)$, and bornite $\left(\mathrm{Cu}_{5} \mathrm{FeS}_{4}\right) . \mathrm{Cu}$ (II) and $\mathrm{Fe}(\mathrm{III})$ will be leached from these ores by acid in the hydrometallurgical process, so $\mathrm{Fe}$ (III) is a common impurity ion in the copper leaching solutions, and it is also one significant ion interfering with the $\mathrm{Cu}$ (II) extraction. Thus, the separation factor for $\mathrm{Cu}(\mathrm{II})$ and $\mathrm{Fe}(\mathrm{III})\left(\beta_{\mathrm{Cu} / \mathrm{Fe}}\right)$ is a key evaluation index for the extractants.

In order to investigate the separation factor in the wide $\mathrm{pH}$ range, the initial concentrations of $\mathrm{Cu}$ (II) and $\mathrm{Fe}(\mathrm{III})$ were set at $1.92 \mathrm{mg} / \mathrm{L}$ and $1.12 \mathrm{mg} / \mathrm{L}$, respectively, to prevent their precipitation at relatively high $\mathrm{pH}$. Other extraction conditions were the same as those in Section 3.2. The effect of $\mathrm{pH}$ on $\beta_{\mathrm{Cu} / \mathrm{Fe}}$ is illustrated in Figure 4.

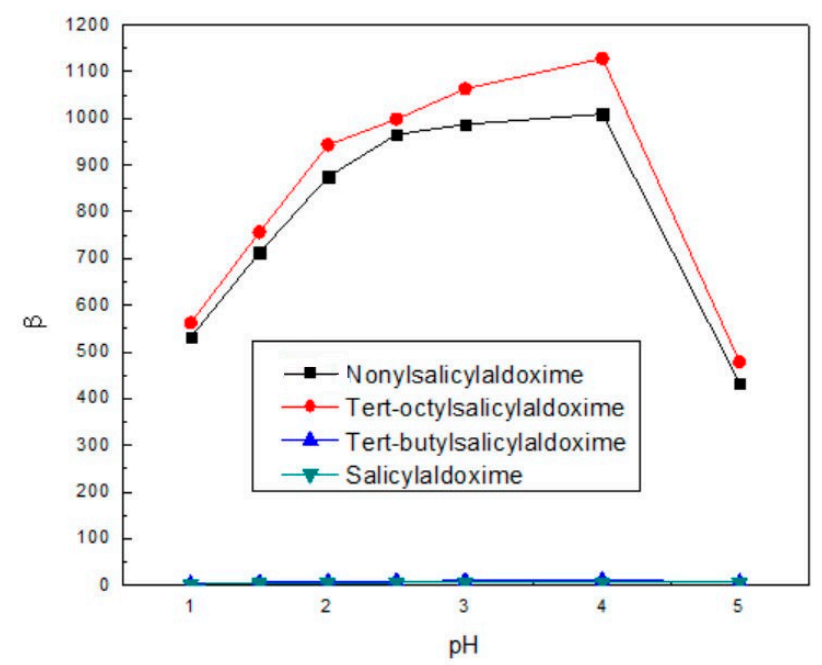

Figure 4. Effect of initial $\mathrm{pH}$ of aqueous phase on the $\beta_{\mathrm{Cu}} / \mathrm{Fe}$.

$\beta_{\mathrm{Cu} / \mathrm{Fe}}$ increased with the rise of $\mathrm{pH}$ and reached a peak of 1128 and 1009 at $\mathrm{pH}=4$ for nonylsalicylaldoxime and tert-octylsalicylaldoxime, respectively, which is consistent with the trend of $\mathrm{Cu}$ (II) extraction efficiency; salicylaldoxime and tert-butylsalicylaldoxime showed much lower $\beta_{\mathrm{Cu} / \mathrm{Fe}}$ at the $\mathrm{pH}$ range studied due to their poor extraction ability for $\mathrm{Cu}$ (II) (Figure 3). tert-Octylsalicylaldoxime showed better $\beta_{\mathrm{Cu} / \mathrm{Fe}}$ than nonylsalicylaldoxime, and this may be caused by the different $\mathrm{R}$ group structures in their molecules. The umbrella structure of the $\mathrm{R}$ group in tert-octylsalicylaldoxime can provide a stronger steric-hindrance effect than the linear chain structure of the R group in nonylsalicylaldoxime, which presumably endows the former with stronger selectivity for $\mathrm{Cu}(\mathrm{II})$. The steric-hindrance effect was also used to explain the selective extraction ability for tertiary amines of the Alamine type [20] and $\beta$-diketone extractants [21].

\subsection{Hydrophobicity $(\log P)$ and Molecular Sizes}

It can be seen from Table 1 that the $\mathrm{R}$ groups have significant impact on the hydrophobicity ( $\log \mathrm{P}$ ) of the extractants. With the increase of carbon atoms in the R groups, the values of Log P 
increase and the chemical reagents become more hydrophobic. Generally, the extractants should have relatively strong hydrophobicity to effectively extract metals [22-24]. It is known that there is no $\mathrm{R}$ group in salicylaldoxime, and the para-directing $\mathrm{R}$ group is tertiary butyl with four carbon atoms in tert-butylsalicylaldoxime (Figure 1), which results in the weaker hydrophobicity than tert-octylsalicylaldoxime and nonylsalicylaldoxime with eight and nine carbon atoms in the R groups, respectively (Table 1). Thus, the latter two reagents present remarkably higher $\mathrm{Cu}$ (II) extraction ability than salicylaldoxime and tert-butylsalicylaldoxime under the same conditions. As the atoms in the $R$ groups increase to eight and nine, the extractants have similar hydrophobicity (Table 1) and they also present similar extraction ability for $\mathrm{Cu}$ (II) (Figure 2). The calculated molecular sizes of the four extractants increase with the augment of the R groups, and this can also be observed from their molecular structures (Figure 1).

Table 1. Hydrophobicity (Log P) and molecular sizes of the extractants.

\begin{tabular}{ccc}
\hline Items & Log $\mathbf{P}$ & Molecular Sizes $\left(\mathbf{n m}^{\mathbf{3}}\right)$ \\
\hline Salicylaldoxime & 1.78 & 100.15 \\
tert-Butylsalicylaldoxime & 3.48 & 170.50 \\
tert-Octylsalicylaldoxime & 5.12 & 241.27 \\
Nonylsalicylaldoxime & 5.61 & 254.12 \\
\hline
\end{tabular}

\section{Conclusions}

The structure of the para-directing $\mathrm{R}$ group linked to the benzene ring determines the $\mathrm{Cu}$ (II) extraction ability of salicylaldoxime-based extractants to a large extent. The extractants with 0-4 carbon atoms in the $\mathrm{R}$ group are not suitable for $\mathrm{Cu}$ (II) extraction, but tert-octylsalicylaldoxime and nonylsalicylaldoxime with eight and nine carbon atoms in the R group, respectively, possess excellent extraction ability for $\mathrm{Cu}(\mathrm{II})$. Moreover, tert-octylsalicylaldoxime and nonylsalicylaldoxime also present satisfactory separation effect for $\mathrm{Cu}$ (II) and $\mathrm{Fe}(\mathrm{III})$, but the former's performance is better than that of the latter due to the special umbrella structure of its $\mathrm{R}$ group, which may provide a stronger steric-hindrance effect for the separation of $\mathrm{Cu}$ (II) and $\mathrm{Fe}(\mathrm{III})$.

The quantum chemical calculation indicates that the hydrophobicity of the extractants is enhanced gradually with the augment of the R groups, which is consistent with the trend of extraction ability of the extractants for $\mathrm{Cu}(\mathrm{II})$. The $\mathrm{Cu}(\mathrm{II})$ extraction ability of the extractants can be speculated according to the quantum chemical calculation.

Acknowledgments: This research was supported by the National Natural Science Foundation of China (21406097 and 51404177). The authors thank Hong Zhong from Central South University for his support on the quantum chemical calculation. The authors also extend special thanks to CSC (China Scholarship Council) for their support.

Author Contributions: Liqing Li conceived and designed the experiments; Yi Wang and Wenjuan An performed the experiments; Liqing Li and Shenxu Bao analyzed the data; Liqing Li contributed materials; Shenxu Bao and Liqing Li wrote the paper.

Conflicts of Interest: The authors declare no conflict of interest.

\section{References}

1. Naderi, H.; Abdollahy, M.; Mostoufi, N.; Koleini, M.J.; Shojaosadati, S.A.; Manafi, Z. Kinetics of chemical leaching of chalcopyrite from low grade copper ore: Behavior of different size fractions. Int. J. Miner. Metall. Mater. 2011, 18, 638-645. [CrossRef]

2. Ramanathan, T.; Ting, Y.P. Selective copper bioleaching by pure and mixed cultures of alkaliphilic bacteria isolated from a fly ash landfill site. Water Air Soil Pollut. 2015, 226, 374-387. [CrossRef]

3. Watling, H.R.; Collinson, D.M.; Li, J.; Mutch, L.A.; Perrot, F.A.; Rea, S.M.; Reith, F.; Watkin, E.L.J. Bioleaching of a low-grade copper ore, linking leach chemistry and microbiology. Miner. Eng. 2014, 56, 35-44. [CrossRef]

4. Naderi, H.; Abdollahy, M.; Mostoufi, N. Kinetics of chemical leaching of chalcocite from low-grade copper ore: size-distribution behavior. J. Min. Environ. 2015, 6, 109-118. 
5. Rotuska, K.; Chmielewski, T. Growing role of solvent extraction in copper ores processing. Physicochem. Probl. Miner. Process. 2008, 42, 29-36.

6. Jain, V.; Pradip; Rai, B. Density functional theory computations for design of salicylaldoxime derivatives as selective reagents in solvent extraction of copper. Trans. Indian Inst. Met. 2016, 69, 135-141. [CrossRef]

7. Pouramini, Z.; Moradi, A. Characterization of 5-nonylsalicylaldoxime production and the effects of modifiers on its extracting/stripping properties. Res. Chem. Intermed. 2012, 38, 2401-2409. [CrossRef]

8. Gameiro, M.L.; Machado, R.M.; Ismael, M.R.; Reis, M.T.; Carvalho, J.M. Copper extraction from ammoniacal medium in a pulsed sieve-plate column with LIX 84-I. J. Hazard. Mater. 2010, 183, 165-175. [CrossRef] [PubMed]

9. Sengupta, B.; Sengupta, R.; Subrahmanyam, N. Copper extraction into emulsion liquid membranes using LIX 984N-C ${ }^{\circledR}$. Hydrometallurgy 2006, 81, 67-73. [CrossRef]

10. Tyman, J.H.; Iddenten, S.J. The synthesis of oxime reagents from natural and semi-synthetic phenolic lipid and alkanoic acid resources for the solvent recovery of copper(II). J. Chem. Technol. Biotechnol. 2005, 80, 1319-1328. [CrossRef]

11. Fuerstenau, D.W.; Herrera-Urbina, R.; McGlashan, D.W. Studies on the applicability of chelating agents as universal collectors for copper minerals. Int. J. Miner. Process. 2000, 58, 15-33. [CrossRef]

12. Reddy, B.R.; Priya, N.D.; Park, K.H. Separation and recovery of cadmium(II), cobalt(II) and nickel(II) from sulphate leach liquors of spent $\mathrm{Ni}-\mathrm{Cd}$ batteries using phosphorus based extractants. Sep. Purif. Technol. 2005, 45, 161-166. [CrossRef]

13. Kul, M.; Çetinkaya, Ü. Recovery of copper by LIX $984 \mathrm{~N}-\mathrm{C}$ from electroplating rinse bath solution. Hydrometallurgy 2009, 98, 86-91. [CrossRef]

14. Reddy, B.R.; Park, K.H.; Mohapatra, D. Process development for the separation and recovery of copper from sulphate leach liquors of synthetic Cu-Ni-Co-Fe matte using LIX 84 and LIX 973N. Hydrometallurgy 2007, 87, 51-57. [CrossRef]

15. Xie, F.; Dreisinger, D. Recovery of copper cyanide from waste cyanide solution by LIX 7950. Miner. Eng. 2009, 22, 190-195. [CrossRef]

16. Ferreira, A.E.; Agarwal, S.; Machado, R.M.; Gameiro, M.L.F.; Santos, S.M.C.; Reis, M.T.A.; Ismael, M.R.C.; Correia, M.J.N.; Carvalho, J.M.R. Extraction of copper from acidic leach solution with Acorga M5640 using a pulsed sieve plate column. Hydrometallurgy 2010, 104, 66-75. [CrossRef]

17. Li, L.; Liao, C.; Tang, Y.; Yang, L. A Tertiary Butyl Salicylaldoxime and Its Synthesis Method. Patent ZL201410444168.1, 3 September 2014.

18. Huang, Z.; Zhong, H.; Wang, S.; Xia, L.; Zhao, G.; Liu, G. Gemini trisiloxane surfactant: Synthesis and flotation of aluminosilicate minerals. Miner. Eng. 2014, 56, 145-154. [CrossRef]

19. Tobiasz, A.; Walas, S.; Landowska, L.; Konefał-Góral, J. Improvement of copper FAAS determination conditions via preconcentration procedure with the use of salicylaldoxime complex trapped in polymer matrix. Talanta 2012, 96, 82-88. [CrossRef] [PubMed]

20. Albrecht, T.W.J.; Addai-Mensah, J.; Fornasiero, D. Effect of pH, concentration and temperature on copper and zinc hydroxide formation/precipitation in solution. In Proceedings of the Chemeca 2011-Engineering a Better World, Sydney, Australia, 18-21 September 2011; pp. 2100-2110.

21. Wilson, A.M.; Bailey, P.J.; Tasker, P.A.; Turkington, J.R.; Grant, R.A.; Love, J.B. Solvent extraction: The coordination chemistry behind extractive metallurgy. Chem. Soc. Rev. 2014, 43, 123-134. [CrossRef] [PubMed]

22. Fu, W.; Chen, Q.; Hu, H.; Niu, C.; Zhu, Q. Solvent extraction of copper from ammoniacal chloride solutions by sterically hindered $\beta$-diketone extractants. Sep. Purif. Technol. 2011, 80, 52-58. [CrossRef]

23. Cierpiszewski, R.; Hebrant, M.; Szymanowski, J.; Tondre, C. Copper(II) complexation kinetics with hydroxyoximes in CTAB micelles. Effect of extractant hydrophobicity and additives. J. Chem. Soc. Faraday Trans. 1996, 92, 249-255. [CrossRef]

24. Radzyminska-Lenarcik, E. Influence of the steric hindrance, ligand hydrophobicity, and DN of solvents on structure and extraction of $\mathrm{Cu}(\mathrm{II})$ complexes of 1-alkyl-2-ethylimidazoles. Sep. Sci. Technol. 2008, 43, 794-814. [CrossRef]

(C) 2017 by the authors. Licensee MDPI, Basel, Switzerland. This article is an open access article distributed under the terms and conditions of the Creative Commons Attribution (CC BY) license (http:/ / creativecommons.org/licenses/by/4.0/). 